CIC. Cuadernos de Información y Comunicación ISSN: 1135-7791

http://dx.doi.org/10.5209/CIYC.55974

\title{
La imagen de la mujer en la prensa deportiva digital: análisis de las portadas de as.com y marca.com ${ }^{1}$
}

Javier Mayoral Sánchez²; Montserrat Mera Fernández ${ }^{3}$

Enviado: 10-06-2016; Aceptado: 17-06-2016

Resumen. En este artículo se analiza la imagen de la mujer en los dos medios digitales deportivos más leídos de España. En las portadas de as.com y marca.com se han contabilizado 5.105 fotografías. Únicamente en el 2,45\% de las imágenes analizadas encontramos a una mujer deportista. Y tan solo en 275 fotografías aparecen mujeres en contextos deportivos. En seis de cada diez fotos sobre mujeres se advierte claramente algún tipo de connotación sexual.

Palabras clave: información deportiva; mujer y deporte; periodismo digital; sexismo; información de género.

[en] The image of women in digital sports press: analysis of the covers of as.com and marca.com

Abstract. This paper analyze the image of women in the two most widely read sports digital media Spain. On the covers of as.com and marca.com 5,105 photographs have been counted. Only in $2.45 \%$ of the images analyzed we found a woman athlete. In six out of ten photos we see some sort of sexual connotation.

Keywords: Sports information; Women and Sport; Digital Journalism; Sexism, Information on Gender.

Sumario. 1. Introducción. 2. Metodología. 3. Resultados. 3.1. Una presencia de mujeres anecdótica, casi invisible. 3.2. Vinculación entre la imagen de la mujer y el deporte. 3.3. La mujer convertida en objeto decorativo o en reclamo sexual. 4. Conclusiones. 5. Referencias bibliográficas.

Cómo citar: Mayoral Sánchez, J.; Mera Fernández, M. (2017). La imagen de la mujer en la prensa deportiva digital: análisis de las portadas de as.com y marca.com, en CIC. Cuadernos de Información y Comunicación 22, 187-201.

\section{Introducción}

En la antigua Grecia la mujer tenía prohibido participar en los Juegos Olímpicos. Igual de taxativo era el veto en los Juegos Píticos, Neménicos e Ítsmicos. No se tra-

1 Este trabajo forma parte de las investigaciones realizadas por GIRP-ENG (Grupo de Investigación en Redacción Periodística: Estilos, Narrativas y Géneros).

2 Universidad Complutense de Madrid.

Email: javier.mayoral@ucm.es

3 Universidad Complutense de Madrid

Email:mmera@ucm.es 
taba solo de que las mujeres no pudieran competir, sino que además se les impedía asistir a las pruebas como público. Quienes violaran esta norma podían ser incluso condenadas a pena de muerte. Según cuenta Pausanias (V, 16, 2-4), había una competición deportiva reservada exclusivamente para las mujeres: los llamados Juegos Hereos.

Un breve repaso histórico permite concluir que "las mujeres en general fueron excluidas y en el mejor de los casos vieron limitada su actividad física por condicionantes sociales y culturales que marcaron sus hábitos y preferencias deportivas" (López, 2011: 42). En los Juegos Olímpicos celebrados en París en el año 1900 se permitió por primera vez la participación de mujeres. Fue algo casi simbólico: 22 mujeres (en solo tres disciplinas) frente a casi mil hombres. Todavía a finales del siglo XX, en los Juegos de Atlanta (Estados Unidos) de 1996, la presencia masculina dobló a la femenina.

Sin embargo, algo importante estaba cambiando en ese tramo final del siglo pasado. En Estados Unidos se constata un mayor protagonismo de la mujer en la prensa deportiva. Algunos autores (Kane y Greendorfer, 1994; Fink y Kensicki, 2002) han señalado que esa mayor atención adolecía, no obstante, de cierta superficialidad e incurría también en viejos estereotipos: la utilización del cuerpo de las deportistas como reclamo sexual (véase, por ejemplo, Bissel y Duke, 2007) o las diferencias en el tratamiento audiovisual o lingüístico en las modalidades masculina y femenina del mismo deporte (Greer, Hardin y Homan, 2009; Jones, 2011).

En cualquier caso, lo que resulta indiscutible es que durante los últimos años la vigilancia académica en relación con este tipo de cuestiones se ha intensificado de forma notable. Así ha ocurrido en la mayoría de países de nuestro entorno cultural. Desde Estados Unidos, donde destacan las investigaciones de Duncan y Messner (1994; 2000), hasta España, que en el último decenio ha multiplicado su producción académica sobre el papel de la mujer en el deporte y sobre la visión que de ella ofrece el periodismo deportivo.

La mayor parte de esas investigaciones ha constatado que los medios de comunicación consideran a la mujer un actor secundario -cuando no invisible- de la información deportiva. Ese es el principal hallazgo del capítulo sexto (Parte $1^{\mathrm{a}}$ ) del $\mathrm{Ma}$ nual elaborado por el Instituto de la Mujer y el Instituto Oficial de Radio y Televisión (López Díez, 2004: 176-179). A esta conclusión llega también Angulo (2007) tras analizar tres medios especializados (Marca, As y Mundo Deportivo). Y otro tanto cabe afirmar de un estudio realizado ese mismo año sobre la sección de deportes de los telediarios (Latorre et al., 2007).

Teniendo en cuenta todo ello, resulta muy pertinente la reflexión que nos dejó la profesora Ana María Vigara (2008: 125): “el sexismo informativo [...], paradójicamente, consiste sobre todo en no informar, en no hacer visible el protagonismo de las mujeres deportistas, tan cierto y se supone que importante, en lo que no les corresponde, como el de los varones (que sí suele encontrar sitio en las páginas deportivas de nuestros periódicos)". Como es lógico, el trabajo de los medios de comunicación no se considera aquí solo en su faceta estrictamente informativa, sino también, desde una perspectiva más sociológica que periodística, por su capacidad para crear identidades contemporáneas (Bernárdez, 2015).

Según el Estudio sobre género y deporte en televisión elaborado en 2008 por el Consejo Audiovisual de Andalucía, el protagonismo de las mujeres en las emisiones televisuales deportivas no alcanza ni siquiera a un 5\% del total. Los datos ofrecidos 
por el Proyecto de Monitoreo Global de Medios muestran oscilaciones considerables entre los años 2000-2010 (véase Sainz de Baranda, 2013b: 109). Esas fluctuaciones no afectan a la idea central de los estudios ya citados, pero añaden si cabe más interés a los trabajos que cambian el cuánto por el cómo. Es decir: aquellas investigaciones que atienden especialmente al modo en que son representadas las mujeres en la prensa deportiva. Es lo que ocurre, por ejemplo, con algunos análisis sobre los estereotipos femeninos (López Díez, 2011), sobre el denominado "sexismo sintáctico" (Rojas, 2010) o sobre la función que desempeñan en las páginas de deportes las fotografias de mujeres "invitadas" (Sainz de Baranda, 2013a: 190-390).

\section{Metodología}

Esta investigación se propone analizar la imagen de la mujer en dos publicaciones digitales especializadas en periodismo deportivo (as.com y marca.com). Para ello ha optado por recurrir a una metodología cuantitativa. Se emplea el clásico análisis de contenido para registrar de forma sistemática el número de fotografías en las que aparece una mujer en la portada o página principal de los dos medios analizados. Se combina esa técnica cuantitativa con un análisis cualitativo que permita describir con la mayor precisión posible en qué contextos informativos se insertan las fotografías registradas. El objetivo fundamental de esa triangulación metodológica es obtener datos sobre aspectos mensurables (en cuántas informaciones, piezas textuales o fotografías aparecen mujeres, acerca de qué disciplinas deportivas, en qué lugares de la portada, etcétera), pero poniendo especial cuidado en reflejar también el tratamiento periodístico que los dos medios digitales estudiados dan a esas fotografías o noticias.

La parte cualitativa de esta investigación se ocupará de asuntos como el tipo de vinculación que mantienen con el deporte las mujeres que aparecen en la prensa deportiva, o la relación entre el título, la imagen y la fotografía, o la indumentaria y la gestualidad de las protagonistas de esas piezas periodísticas. Muchas de estas cuestiones resultan difícilmente cuantificables, así que se ha optado por emplear como métodos complementarios (y en cierto modo auxiliares) el tradicional análisis del discurso y los estudios culturales.

Tabla 1. Ficha de análisis

\begin{tabular}{|l|l|}
\hline NOTICIAS EN PORTADA & \\
\hline FOTOGRAFÍAS PORTADA & \\
\hline REFERENCIA INFORMATIVA & \\
\hline DEPORTE & \\
\hline UBICACIÓN & \\
\hline TITULAR & \\
\hline CONTENIDO INFORMATIVO & \\
\hline ELEMENTOS ICÓNICOS & \\
\hline VÍDEO & \\
\hline FOTOGRAFÍA & \\
\hline
\end{tabular}




\begin{tabular}{|l|l|}
\hline SUPERFICIE & \\
\hline PROTAGONISTA & \\
\hline ENTORNO & \\
\hline INDUMENTARIA & \\
\hline GESTUALIDAD & \\
\hline RELACIÓN CON DEPORTE & \\
\hline COMENTARIO & \\
\hline
\end{tabular}

Fuente: elaboración propia

La Tabla 1 recoge todos los aspectos que han sido considerados en este estudio. Se empleó exactamente la misma ficha de análisis en un trabajo ${ }^{4}$ realizado con idéntica metodología a finales de 2010. No se han introducido cambios para que, llegado el momento, se puedan comparar los datos de 2010 con los obtenidos en 2016. El primer trabajo de campo se desarrolló entre el 2 y el 16 de noviembre. El segundo trabajo de campo, que constituye la base de este estudio, se inició el 4 de enero y finalizó el 17 de enero de 2016. Para la determinación de esas fechas se ha tenido muy en cuenta la programación deportiva. Se evitó, por ejemplo, la primera quincena de noviembre de 2015 porque coincidía con un parón en la Liga de fútbol por un partido de la selección española. El objetivo era analizar un periodo de actividad deportiva normal, sin acontecimientos extraordinarios que pudieran alterar los resultados del estudio.

Para configurar la muestra se han seleccionado los dos cibermedios deportivos con más lectores en España. Según los datos del EGM de 2016 (primera oleada), marca.com encabeza esa clasificación con 4.705 .000 visitantes únicos al día. Le sigue as.com (2.443.000 visitantes únicos). Los sitios web de Mundo Deportivo y Sport se sitúan ya a gran distancia (por debajo ambos del 1.200 .000 visitantes únicos). Se ha preferido la versión digital, en lugar del soporte en papel, por varios motivos: porque, al buscar un público más joven, es verosímil que refleje mejor los cambios sociales en relación con el deporte femenino; porque no está tan sometido a las restricciones de espacio que, sin embargo, son habituales en el periodismo impreso en papel; $y$, por último (y en relación con lo anterior), porque el periodismo digital suele prestar más atención a la fotografía, lo cual resulta decisivo en una investigación cuyo objeto de estudio es precisamente la imagen de la mujer en el deporte.

Para concluir este apartado sobre metodología, conviene aclarar cómo se ha dividido el espacio de las portadas. Se han establecido tres tramos en cada página web. El primero (que ocupa todas las columnas disponibles, de izquierda a derecha, y el primer tercio de la portada, de arriba hacia abajo) se ha denominado "Ubicación 1". El segundo (el tramo central en la barra de desplazamiento vertical) se ha llamado "Ubicación 2". Y el tercero (tercio inferior de la portada), "Ubicación 3". Este reparto del espacio, que no ayuda a introducir matices en relación -por ejemplo- con columnas de entrada o de salida, presenta la gran ventaja de que permite comparar portadas de diferente dimensión, puesto que se consideran tres partes que en realidad representan porcentajes respecto al total del espacio disponible.

$4 \quad$ Los resultados de ese estudio, que no fue publicado en revistas académicas, se expusieron en el I Congreso Internacional de Ética de la Comunicación (celebrado en Sevilla en marzo de 2011). 
Puede decirse que, en general, una mayor valoración de los materiales periodísticos relativos al deporte femenino supondrá la inclusión de más noticias relacionadas con mujeres deportistas en la "Ubicación 1", ya que es ahí donde los periodistas suelen colocar las noticias más importantes o más recientes. En sentido contrario, la "Ubicación 3" denotará una menor jerarquía de las noticias incluidas en este último espacio de la portada.

\section{Resultados}

Durante las dos semanas de análisis (entre el 4 y 17 de enero de 2016, ambos incluidos) se han registrado 5.342 piezas periodísticas. El 95,56\% de ellas contenía una fotografía o algún otro tipo de recurso icónico. La imagen es ya, por tanto, un elemento de identificación periodística tan importante como el titular. Salvo casos excepcionales (tablas con resultados de partidos, por ejemplo), cada título va acompañado de su correspondiente fotografía. Durante los últimos años la prensa ha reducido de forma drástica el espacio dedicado a la entradilla clásica. En el caso concreto de marca.com incluso han desaparecido esas primeras líneas de texto: en la portada solo recurre al título (precedido a veces de un antetítulo) y a una o varias fotos.

El Gráfico 1 muestra que as.com publica en su página principal muchos más textos y fotografías que marca.com. Si nos ceñimos a las fotografías, la aportación de as.com supone el $61,70 \%$ de la muestra. Esta cabecera periodística coloca en su portada una media diaria de 225 fotografías y casi 240 piezas textuales. La página principal de marca.com contiene 143 piezas y casi 140 fotos por día. Conviene tener en cuenta estos datos porque la impresión inicial de un lector-incluso si se trata de un lector habitual- puede ser muy distinta. En principio cabe aventurar que en esa portada hay menos textos y fotos, quizá porque no es frecuente que el lector llegue hasta la parte inferior de esa página web.

Gráfico 1. Piezas textuales y fotografías publicadas en portada.

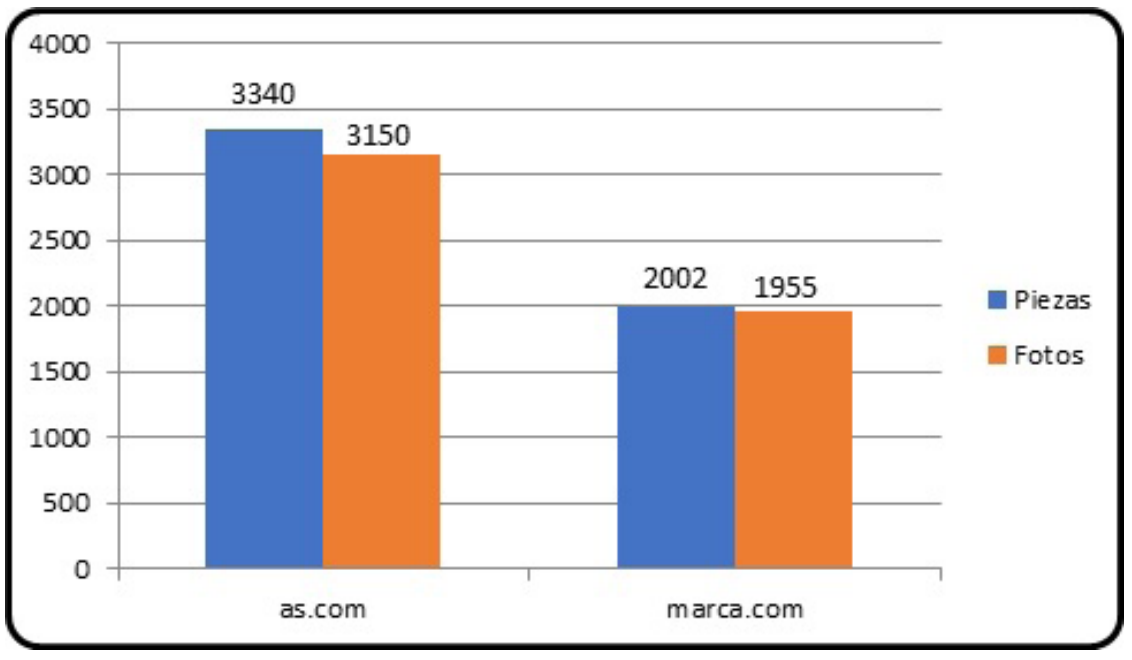

Fuente: elaboración propia 
En este estudio se considera "pieza textual" cualquier contenido periodístico encabezado por un titular (completo o con al menos un título). Es importante matizar que muchos de esos textos no son, en sentido estricto, informaciones o noticias, puesto que con frecuencia estas portadas incluyen encuestas, foros, opiniones, concursos o simples curiosidades sin desarrollo textual alguno.

\subsection{Una presencia de mujeres anecdótica, casi invisible}

Los datos que se acaban de ofrecer permiten informar sobre el tamaño de la muestra analizada, pero sobre todo resultan útiles para situar en su justa dimensión los valores numéricos incluidos en el Gráfico 2. Según se acaba de ver, en este trabajo se han registrado 5.105 fotografías publicadas en las portadas de as.com y marca.com. Pues bien: de esas 5.105 imágenes, solo 584 incluyen a algún personaje femenino. No se llega, por tanto, ni siquiera al $11,5 \%$ del conjunto de fotografias analizadas.

Gráfico 2. Personajes de las fotografías analizadas.

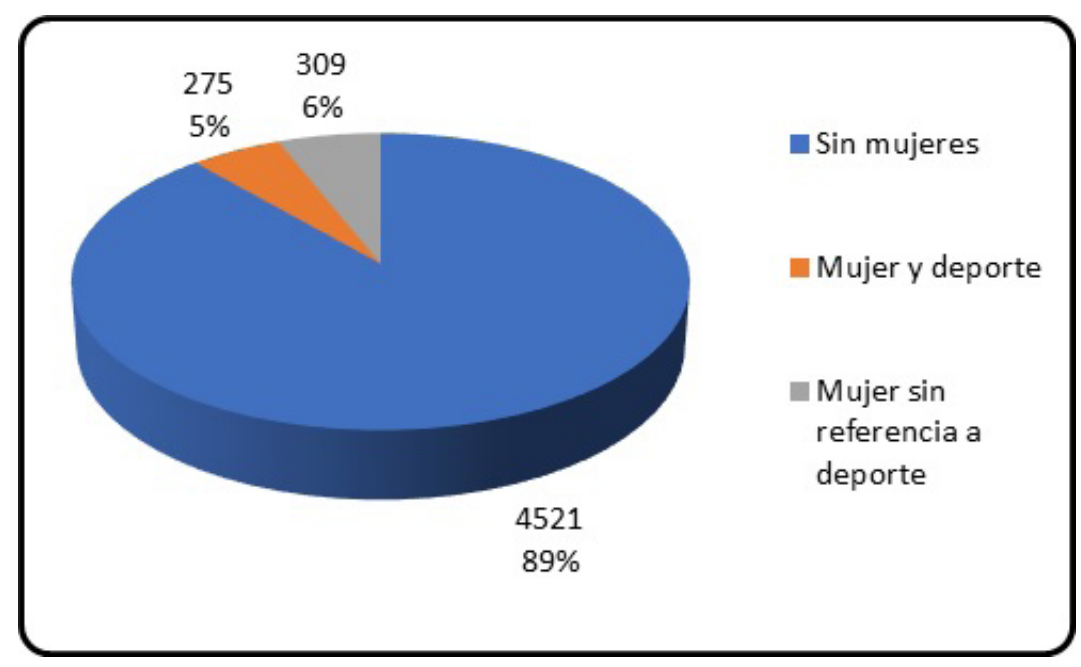

Fuente: elaboración propia

Hay que tener en cuenta que en esas 584 fotos en las que aparece alguna mujer el protagonista puede seguir siendo un hombre. Lo único que se afirma es que al menos en esa imagen se introduce un personaje femenino. Como se verá en el apartado siguiente, en muchas de esas situaciones la mujer aparece por casualidad, hasta el punto de que ni siquiera se da una mínima pista de quién es o de por qué se encuentra en esa escena. En las otras 4.521 fotografias, en cambio, todo es masculinidad.

El segundo matiz resulta incluso más importante que el anterior: solo en 275 casos (el 5,38\% de la muestra) se reproducen imágenes de mujeres en un contexto ligado al deporte. Por lo tanto, las restantes 309 fotos $(6,05 \%$ del total) que se consignan en el Gráfico 2 hacen referencia a imágenes que nada tienen que ver con competiciones o actividades deportivas. En los dos apartados siguientes se verá con 
más detalle qué tipo de significados pragmáticos, estereotipos y roles sociales pueden asociarse a este grupo de recursos icónicos tan -en principio- insospechables: imágenes publicadas con cierta regularidad en la prensa deportiva pero que son por completo ajenas al deporte.

En cuanto a la ubicación de las 584 fotografías con algún tipo de presencia femenina, el Gráfico 3 señala las posiciones preferidas por los dos medios analizados. En el primer tramo de la web (denominado aquí "Ubicación 1") suelen situarse los contenidos más valorados, los más relevantes. Los responsables de as.com colocan ahí el 22,75\% de las imágenes que incluyen algún personaje femenino. No obstante, algunos días (el viernes 15 de enero, por citar un ejemplo de as.com, o el 9 de enero en marca.com) no se incluye ni una sola imagen de mujer en todo este tramo inicial. El caso de marca.com resulta aún más llamativo: solo el 8,69\% de las piezas consideradas en este Gráfico 3 aparece en esa primera parte de la portada.

Gráfico 3. Ubicación de las fotografías en las portadas.

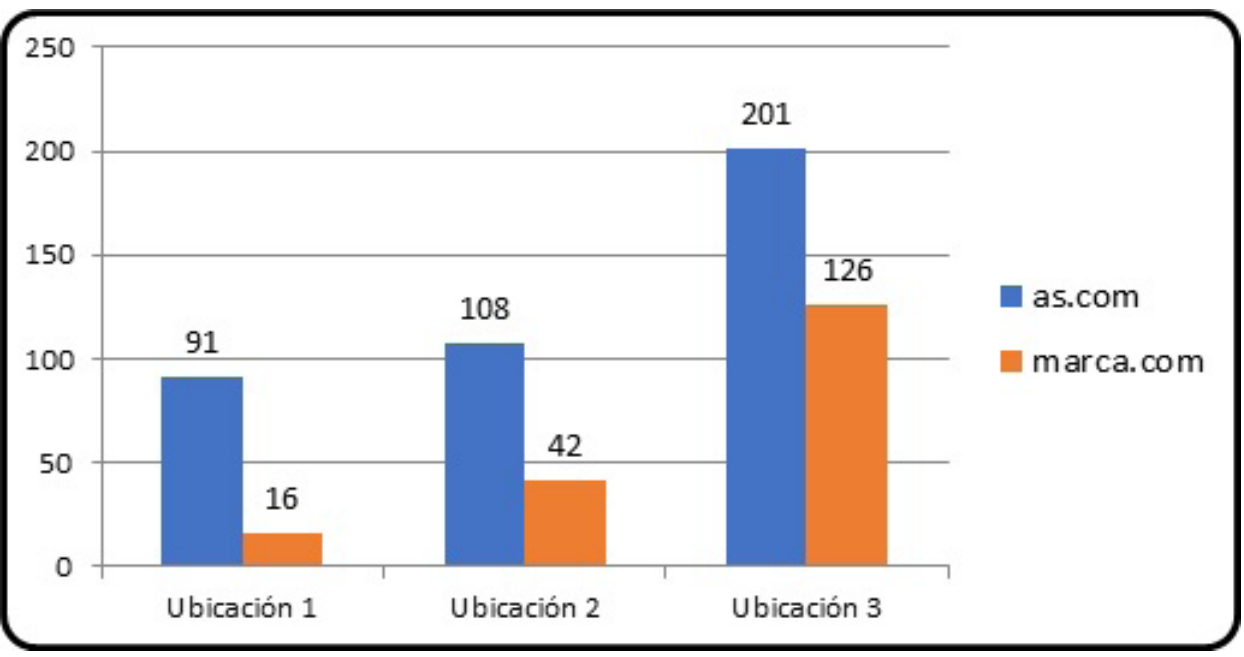

Fuente: elaboración propia

El porcentaje de marca.com correspondiente a esta "Ubicación 1" $(8,69 \%)$ se acerca mucho al resultado global (as.com y marca.com) obtenido en relación con esta parte inicial de portada en el trabajo de campo de 2010 (9,96\%). Tampoco hay grandes divergencias si se observa la parte central de la web. En la "Ubicación 2" se localizaba el $29,08 \%$ de las piezas en 2010 , mientras que en el trabajo de campo de 2016 ese porcentaje baja hasta un 25,68\%.

En cualquier caso, lo que parece indiscutible es que tanto as.com como marca. com prefieren emplazar sus fotografias y noticias sobre mujeres en la parte inferior de la portada, donde en principio suelen encontrar cobijo los contenidos periodísticos de menor enjundia. Es verdad que son contenidos destacados por el mero hecho de aparecer en portada, pero en un nivel jerárquico notablemente inferior al de los dos tramos superiores. En esta denominada "Ubicación 3" hallamos el 50\% de las fotos de as.com y el $68,5 \%$ de las publicadas por marca.com. En conjunto, ahí se sitúa el $56 \%$ de las 584 piezas consideradas $(60,96 \%$ en 2010$)$. 
Para entender esta nítida preferencia por la "Ubicación 3" conviene anticipar que la mayoría de las piezas protagonizadas por mujeres -especialmente en este tramo inferior de la portada- desempeña en los dos cibermedios analizados una función especial: ni informativa ni realmente periodística. Estos contenidos se distribuyen en la parte final de la web para anclar la atención del lector con imágenes y textos que no obedecen a los criterios periodísticos clásicos de novedad, relevancia del personaje, trascendencia pública de lo acontecido, etcétera. Se trata, en definitiva, de piezas potencialmente atractivas para un determinado perfil de lector, pero esencialmente distintas al resto de informaciones periodísticas en las que el protagonista es un hombre.

\subsection{Vinculación entre la imagen de la mujer y el deporte}

De las 5.105 fotografías registradas en este trabajo, como ya se anotó en el apartado anterior, solo 275 incluyen a algún personaje femenino en un contexto relacionado siquiera mínimamente con el deporte. ¿Con qué deportes? En primer lugar, con el fútbol. La Tabla 2 no deja lugar a dudas. También en el ámbito femenino el fútbol es el deporte preferido (105 piezas, casi un 18\% de las 584 en las que aparecen mujeres). Lo llamativo aquí, no obstante, es el protagonismo de las disciplinas con las que compite: el tenis (casi 50 fotografías), el baloncesto (32 fotos) y el atletismo (23).

Tabla 2. Deportes relacionados con las fotografías de mujeres.

\begin{tabular}{|c|c|c|c|}
\hline & as.com & marca.com & TOTAL \\
\hline Fútbol & $\begin{array}{c}76 \\
(19 \%)\end{array}$ & $\begin{array}{c}29 \\
(15,76 \%)\end{array}$ & $\begin{array}{c}105 \\
(17,98 \%)\end{array}$ \\
\hline Tenis & $\begin{array}{c}27 \\
(6,75 \%)\end{array}$ & $\begin{array}{c}22 \\
(11,96 \%)\end{array}$ & $\begin{array}{c}49 \\
(8,39 \%)\end{array}$ \\
\hline Baloncesto & 10 & 22 & 32 \\
& $(2,5 \%)$ & $(11,96 \%)$ & $(5,48 \%)$ \\
\hline Atletismo & 13 & 10 & 23 \\
& $(3,25 \%)$ & $(5,43 \%)$ & $(3,94 \%)$ \\
\hline Boxeo & 12 & 0 & 12 \\
& $(3 \%)$ & $(0 \%)$ & $(2,05 \%)$ \\
\hline Fitness & 6 & 2 & 8 \\
& $(1,5 \%)$ & $(1,08 \%)$ & $(1,37 \%)$ \\
\hline Natación & 4 & 1 & 5 \\
& $(1 \%)$ & $(0,54 \%)$ & $(0,85 \%)$ \\
\hline Waterpolo & 3 & 2 & 5 \\
& $(0,75 \%)$ & $(0,10 \%)$ & $(0,85 \%)$ \\
\hline Otros & 21 & 15 & 36 \\
& $(5,25 \%)$ & $(8,15 \%)$ & $(6,16 \%)$ \\
\hline
\end{tabular}

Fuente: elaboración propia.

En el caso del tenis y del atletismo se advierte cierta semejanza respecto a los datos obtenidos en el trabajo de campo de 2010. También entonces sobresalían esos 
dos deportes. Hay, sin embargo, una diferencia fundamental: donde ahora vemos 49 y 23 fotos antes veíamos 11 y 9, respectivamente. Esos datos ilustran bien el cambio experimentado. La presencia de la mujer en contextos vinculados al deporte ha aumentado considerablemente, puesto que en 2010 solo en el 1,89\% en las piezas registradas aparecía alguna mujer deportista.

La Tabla 3 resulta a este respecto más nítida, pues no aporta datos sobre contextos informativos relacionados con el deporte (como sucede en la Tabla 2), sino directamente sobre la profesión de las mujeres fotografiadas. Puede ocurrir, por ejemplo, que se publique la fotografía de una chica junto a su novio futbolista o que se publique la imagen de una futbolista jugando con su equipo. En el primer caso puede suceder que el contexto informativo tenga relación directa con el fútbol (porque el futbolista, supongamos, está lesionado). En el segundo caso la situación es distinta: la mujer es la protagonista de la imagen en su condición de deportista.

Tabla 3. Rol de las mujeres que aparecen en fotografías.

\begin{tabular}{|c|c|c|c|}
\hline & as.com & marca.com & TOTAL \\
\hline Actriz & $\begin{array}{c}86 \\
(21,5 \%)\end{array}$ & $\begin{array}{c}32 \\
(17,39 \%)\end{array}$ & $\begin{array}{c}118 \\
(20,20 \%)\end{array}$ \\
\hline Modelo & 82 & 18 & 110 \\
& $(20,5 \%)$ & $(9,78 \%)$ & $(18,83 \%)$ \\
\hline Esposa o novia & 59 & 16 & 75 \\
& $(14,75 \%)$ & $(8,69 \%)$ & $(12,84 \%)$ \\
\hline No señalado & 51 & 7 & 58 \\
& $(12,75 \%)$ & $(3,80 \%)$ & $(9,93 \%)$ \\
\hline Tenista & 27 & 22 & 49 \\
& $(6,75 \%)$ & $(11,95 \%)$ & $(8,39 \%)$ \\
\hline Animadora & 6 & 16 & 22 \\
& $(1,5 \%)$ & $(8,69 \%)$ & $(3,76 \%)$ \\
\hline Atleta & 13 & 6 & 19 \\
& $(3,25 \%)$ & $(3,26 \%)$ & $(3,25 \%)$ \\
\hline Futbolista & 10 & 8 & 18 \\
& $(2,5 \%)$ & $(4,35 \%)$ & $(3,08 \%)$ \\
\hline Presentadora & 13 & 4 & 17 \\
& $(3,25 \%)$ & $(2,17 \%)$ & $(2,91 \%)$ \\
\hline Aficionada & 12 & 4 & 16 \\
& $(3 \%)$ & $(2,17 \%)$ & $(2,74 \%)$ \\
\hline Cantante & 3 & 12 & 15 \\
& $(0,75 \%)$ & $(6,52 \%)$ & $(2,57 \%)$ \\
\hline \hline
\end{tabular}

Fuente: elaboración propia.

Al confrontar esta Tabla 3 con la Tabla 2, salta a la vista que el fútbol es un deporte en el que la mujer suele asociarse a varios roles: el de jugadora solo se documenta en 18 fotografías, de modo que se pierden 87 imágenes de las 105 citadas a propósito 
del fútbol en la tabla anterior. Para entender qué sucede lo mejor es examinar la tercera categoría de esta Tabla 3: nada menos que en 75 fotografías vemos a una mujer que acompaña a un deportista (casi siempre futbolista) porque es su esposa o su novia. Tanto marca.com como as.com se refieren a estas mujeres en títulos y antetítulos como "wags" (acrónimo de "esposas y novias", en inglés).

"Las más bellas del Balón de Oro", titula marca.com el lunes 11 de enero. Un día después as.com publica varias piezas dedicadas también a las novias de los futbolistas que han asistido a esa ceremonia. Conviene insistir en que el contexto informativo puede considerarse no ajeno a lo deportivo (se concede un premio al mejor jugador de la temporada), pero la presencia de la mujer en esas fotos, como muestra el titular citado, nada tiene que ver con el ámbito estrictamente deportivo.

Si se destaca la imagen de la novia de Sergio Ramos o la fotografía de la esposa de Lionel Messi es porque el medio digital entiende que son mujeres bellas, atractivas. Sobre la presentadora de esta ceremonia leemos lo siguiente en as.com (12/01/2016) "La guapísima periodista volvió a presentar la gala del Balón de Oro. El año pasado la vimos espectacular y este año no nos ha defraudado". El titular que acompaña a ese breve texto tampoco ofrece dudas: "Kate Abdo vuelve a enamorar en la gala del Balón de Oro". Como se puede comprobar en la Tabla 3, en las portadas analizadas se han contabilizado 17 fotografías de presentadoras (por 18 imágenes de mujeres futbolistas). En todos los casos surge el rasgo de la belleza como cualidad esencial de las protagonistas de esas imágenes.

La faceta estrictamente deportiva de estas imágenes, por lo tanto, la encontramos en las categorías de "futbolista" (18 fotos), "atleta" (19) y tenista (49). De hecho el tenis es el único deporte femenino en el que se aprecia una cobertura con cierta continuidad. Aunque ni siquiera eso garantiza un enfoque periodístico de carácter informativo: "Las siete tenistas más sexys del momento actual", titula marca.com el 12 de enero de 2016. Antes habíamos visto en as.com durante siete días (desde el 4 hasta el 10 de enero, ambos incluidos) este otro titular: "Ana Ivanovic: la tenista más sexy de 2015 ". En este caso la foto de portada permitía enlazar con una galería de 35 fotografías en las que la tenista posa como si fuera una modelo.

Gráfico 4. Profesiones y roles predominantes..

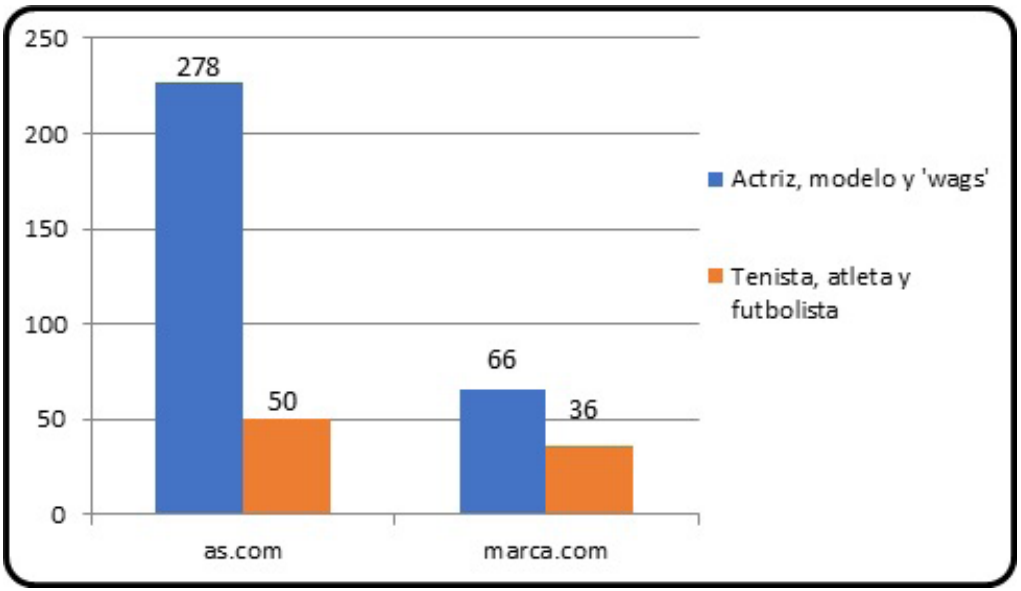

Fuente: elaboración propia 
Solo en 125 fotografías encontramos a mujeres deportistas. Esto supone un 2,45\% de las 5.105 fotos registradas en las dos portadas. Si la Tabla 3 mostraba sin ambages la atracción de la prensa deportiva digital por las imágenes de modelos y actrices, el Gráfico 4 permite observar cómo esos roles se imponen de forma rotunda, especialmente en as.com, a otros más vinculados a actividades o competiciones deportivas. Se obvian aquí, para simplificar, las categorías de "presentadora", "cantante", "animadora" o "aficionada". Se utilizan solo las de "modelo", "actriz" y "novia o esposa". Al otro lado, se buscan las tres categorías asociadas al deporte con mayor número de fotografías contabilizadas en el trabajo de campo: "tenista", "atleta" y "futbolista". La robustez de cada uno de esos grupos queda representada en el Gráfico 4, que ni siquiera ha tenido en cuenta los casos ya citados en los que una tenista aparece posando como modelo, más que en su condición de profesional del deporte.

Por último, merece al menos un comentario la categoría que en la Tabla 3 se denominó "No señalado", en referencia al rol asumido por los personajes fotografiados. Se trata de 58 imágenes (es decir, un 10\% de las 584 analizadas) en las que aparecen mujeres de las que no se aporta ninguna información. No se dice quiénes son ni por qué están ahí. Simplemente están. Como personajes secundarios, como acompañantes, como atrezo. No son nombradas ni identificadas porque resultan accesorias en esas fotografías, porque su presencia en las imágenes es fruto de la casualidad, no del protagonismo que asumen en la escena retratada.

\subsection{La mujer convertida en objeto decorativo o en reclamo sexual}

El 9 de enero de 2016 as.com informa de que ha muerto la primera mujer conductora de Fórmula 1. Ese sábado se publica en la portada una fotografía la italiana María Teresa de Filippis. El día 6, y en el mismo medio, el lector encuentra la fotografía de la periodista Maite Martín, que publica un texto de opinión sobre el Rayo Vallecano y su entrenador Paco Jémez. Ese miércoles la portada de marca.com cuenta que la exdoctora del Chelsea, Eva Carneiro, ha denunciado al club por "despido improcedente". El jueves 14 de enero los lectores de marca.com pueden leer un interesante texto sobre la conciliación familiar de los deportistas. Un día después as.com entrevista a la futbolista Vero Boquete, que prepara junto a sus compañeras de la selección española un importante partido contra Montenegro.

Ninguna de esas informaciones debe ser minimizada. Si observamos con atención la muestra de 2010, resulta evidente que los medios deportivos analizados en 2016 han intentado y conseguido aumentar su oferta informativa sobre mujeres. Particularmente en tenis, fútbol y atletismo. No sería razonable discutir esa evolución. En los apartados anteriores se ha señalado ya que estas noticias siguen siendo poco frecuentes, en especial si se comparan con las publicadas sobre hombres o con las protagonizadas por mujeres que no son deportistas.

El objetivo de ofrecer visibilidad al deporte practicado por mujeres sigue siendo un reto muy importante para la prensa deportiva digital. Hay mucho camino que recorrer aún. El margen de mejora, como se ha podido comprobar en los apartados anteriores, es todavía enorme. Sin embargo, al tiempo que se avanza en ese sentido, urge una reflexión sobre otro aspecto no menos esencial: la imagen de la mujer (sea o no en relación con el deporte) que proyectan estos medios de comunicación. De poco sirve que se progrese en lo primero si la segunda cuestión queda aparcada ad eternum. 
El jueves 7 de enero de 2016 marca.com publica una noticia sobre unos supuestos comentarios machistas lanzados por un árbitro de fútbol a las jugadoras de un equipo. El titular ${ }^{5}$ dice lo siguiente: "Un árbitro, a las chicas del Albacete: 'Toma una amarilla, por guapa"”. Más allá del texto informativo, merece la pena revisar los comentarios que suscita esa noticia en los lectores. Uno de ellos (en el comentario número 100) recurre al sarcasmo: "Me parece vergonzoso lo que ha hecho este árbitro, las chicas eran todas feas con ganas". Muchos otros comentarios similares desarrollaban esa misma idea, casi siempre con un tono más agresivo y hosco.

Cabe preguntarse si no es el propio medio de comunicación el que está contribuyendo a que los lectores reaccionen de ese modo. Y no por esta noticia concreta (que más bien parece denunciar un comportamiento machista), sino por la multitud de textos y de imágenes en los que la mujer aparece como un elemento ornamental, pasivo, un ser que no hace nada pero ha de ser bello. En cualquier circunstancia, en cualquier contexto. Empezando por el propio periodismo: "Las periodistas rubias más bellas del deporte" (marca.com, 17/01/2016). Y por supuesto en el fútbol: "El Lorca Féminas se destapa en 2016" (sobre un calendario erótico de futbolistas, en marca.com, 13/01/2016). En todo lo que rodea al fútbol, cabría añadir: "El sensual baile de Daniela Ospina, la mujer de James [jugador del Real Madrid]" (as.com, 9/01/2016); "El baile más sensual de la novia de Crouch [futbolista inglés]" (marca. com, 4/01/2016); "El baile de infarto que encandiló a Jefferson Farfán [futbolista peruano]" (marca.com, 12/01/2016).

Gráfico 5. La imagen de la mujer como reclamo sexual.

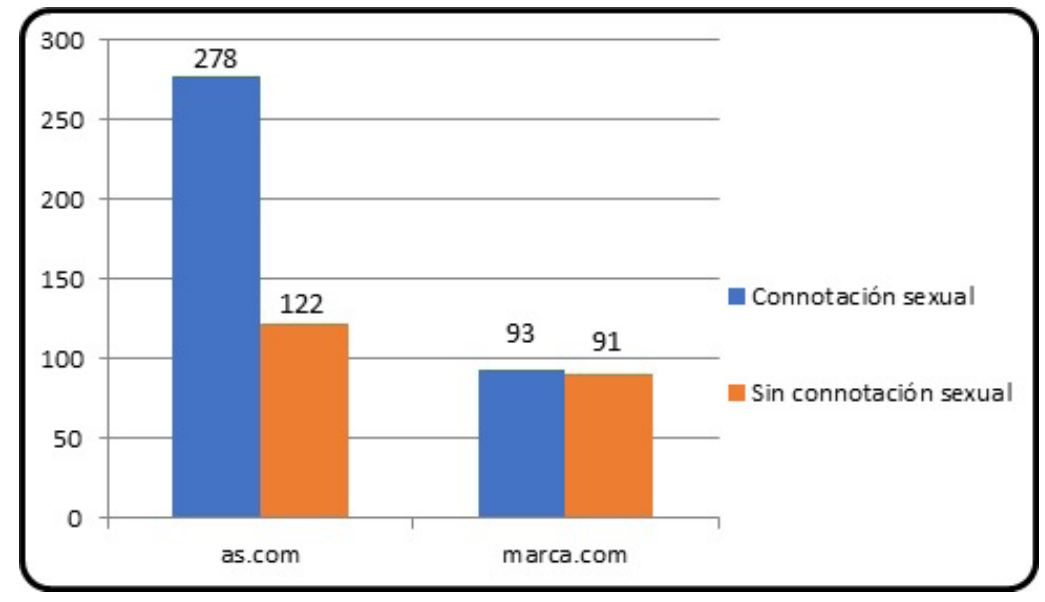

Fuente: elaboración propia

El Gráfico 5 muestra hasta qué punto las fotografías publicadas en las portadas de as.com y marca.com reflejan a una mujer mucho más cercana a lo sexual que a lo estrictamente deportivo. El $63,5 \%$ de las imágenes analizadas (371 fotografías) contiene algún elemento que certifica esa connotación sexual. A menudo emerge incluso con los titulares: "Las mineras más sexys de la NBA", titula marca.com el 4 de

Puede consultarse el texto completo de la noticia en el siguiente enlace: http://www.marca.com/futbol/futbol-femenino/2016/01/07/568e551e268e3ee6488b458a.html. 
enero. Otras veces, en los breves textos que acompañan a esos titulares, como en este que publicó as.com el 8 de enero: "Emily Ratajkowski es el pibón del momento en la redes sociales con este, su último vídeo, no tiene límites, ella solita se presenta ante sus seguidores enseñando todo lo que tiene". Y, en cualquier caso, esa vinculación con lo erótico se suele plasmar ya definitivamente en las fotografías.

De las 371 fotografías en las que se aprecia con claridad esa connotación sexual, la mayoría (exactamente 183) centra su atención en el pecho de las mujeres fotografiadas. No es extraño que incluso el titular procure focalizar la atención del lector: "El día que Twitter alucinó con el escote de Ronda Rousey" (as.com, 11/01/2016). Paradójicamente se escribe "escote", con cierto eufemismo. Y algo similar sucede con las propias imágenes. Las fotos de la portada tienden a sugerir una desnudez que, al pinchar en el enlace, se muestra ya de un modo mucho más explícito.

En estas fotografías cargadas de connotaciones sexuales, como se ha señalado ya, aparecen a veces algunas deportistas que posan ante la cámara. Sin embargo, lo habitual es que las protagonistas de estas imágenes sean actrices o modelos. Resulta muy curioso el empeño de los dos medios analizados en relacionar al personaje fotografiado con algún tipo de actividad deportiva. Sea la que fuere. Se aprovecha cualquier detalle, por absurdo o nimio que parezca, para insertar en el ámbito deportivo a esa mujer cuyo desnudo se pretende mostrar.

El día 13 de enero as.com lleva a su portada a una modelo que ha querido "felicitar a Messi" en las redes sociales. Y para ello se ha desnudado. Un día después el desnudo en ese mismo medio corresponde a Sidonie Biemont, de la que se dice que es "la ardiente musa del Sevilla". El 7 de enero marca.com publica una galería de sensuales fotos de "9 deportistas que se han quedado solteras en 2015". El miércoles 6 de enero as.com presenta a sus lectores a una modelo que aparece en portada semidesnuda. De ella se dice "que le gustan mucho los deportes". El día anterior le tocó el turno a una mujer que nada tenía que ver con el deporte profesional, pero, según as.com, era "aficionada al baloncesto". En el caso de marca.com, hay una especie de sección en la que se recopilan las imágenes más impactantes de la NBA. Impactantes por su contenido sexual, como el propio medio advierte: "El zoom más extremo y sensual a una jornada de la NBA".

\section{Conclusiones}

La presencia de la mujer en contextos periodísticos vinculados al deporte sigue siendo absolutamente minoritaria, casi excepcional. De las 5.105 imágenes contabilizadas en las portadas de as.com y marca.com, solo 275 (el 5,38\%) muestran a mujeres en relación con alguna actividad deportiva. $Y$ tan solo en el 2,45\% de las fotografías encontramos a una mujer deportista. En otras 309 fotos (el 6,05\% de la muestra) aparecen mujeres en contextos que nada tienen que ver con el deporte.

Tanto as.com como marca.com acostumbran a situar sus fotografías y noticias sobre mujeres en la parte inferior de la portada, donde se suelen colocar los contenidos menos relevantes que se publican en la web. En ese tramo final (denominado en este trabajo "Ubicación 3") se localiza el 56\% de las 584 fotos en las que se localiza a alguna mujer, sea o no deportista.

De esas 584 fotografías, la mayoría (105 piezas, casi un 18\%) tiene relación con el fútbol. Ese dato contrasta con el número de futbolistas fotografiadas: solo 18. Para 
entender esa aparente contradicción conviene advertir que muchas de las mujeres que aparecen vinculadas al fútbol no son futbolistas, sino son novias o esposas de futbolistas. Esto ocurre en 75 imágenes. Las profesiones más frecuentes en las fotografías analizadas - por delante de ese rol de "novia o esposa de deportista"- son las siguientes: modelo (118 imágenes) y actriz (110). En otras palabras: cuatro de cada diez fotografías de mujeres corresponden a modelos o actrices.

Ese último dato es importante para entender qué imagen de mujer proyectan a la sociedad estos dos medios especializados en información deportiva. No obstante, conviene completarlo con esta otra información: el 63,5\% de las imágenes analizadas en este estudio contiene elementos que aportan a la fotografía algún tipo de connotación sexual. De ahí que esta prensa deportiva acabe por construir una imagen de lo femenino muy ligada a viejos estereotipos. En lugar de una deportista que participa en competiciones (fútbol, tenis, baloncesto), en las portadas de estos dos medios encontramos en la inmensa mayoría de los casos a una mujer pasiva, que posa para el fotógrafo, que casi siempre muestra su belleza o su desnudez, y que se convierte, en definitiva, en una especie de objeto decorativo o de reclamo sexual para atraer la atención de un determinado perfil de lectores.

\section{Referencias bibliográficas}

Angulo, Marta (2007), Las imágenes de las deportistas en los medios de comunicación, Ministerio de Educación y Ciencia, Consejo Superior de Deportes, Madrid.

Bernárdez Rodal, Asunción (2015), Mujeres en medio(s). Propuestas para analizar la comunicación masiva con perspectiva de género, Editorial Fundamentos, Madrid.

Bissell, Kimberly L., Duke, Andrea M. (2007), "Bump, set, spike: An analysis of commentary and camera angles of women's beach volleyball during the 2004 summer Olympics", en Journal of Promotion Management, 13(1-2), 35-53.

Consejo Audiovisual de Andalucía (2008), Estudio sobre género y deporte en televisión, Sevilla.

Duncan, Margaret Carlisle y Messner, Michael (1994), Gender stereotyping in televised sports: A followup to the 1989 study, The Amateur Athletic Foundation of Los Angeles, Estados Unidos.

Duncan, Margaret Carlisle y Messner, Michael (2000), Gender in televised sports: 1989, 1993 and 1999, The Amateur Athletic Foundation of Los Angeles, Estados Unidos.

Fink, Janet y Kensicki, Linda (2002), "An imperceptible difference: Visual and textual constructions of femininity in Sports Illustrated and Sports Illustrated for Women", en Mass Communication and Society, 5, 317-339. [http://dx.doi.org/10.1207/ S15327825MCS0503_5].

Greer, Jennifer D., Hardin, Marie, Homan, Casey (2009), "Naturally' less exciting? Visual production of men's and women's track and field coverage during the 2004 Olympics", en Journal of Broadcasting and Electronic Media, 53(2), 173-189.

Jones, Amy H. (2011), "Visual and verbal gender cues in the televised coverage of the 2010 winter Olympics", en International Journal of Interdisciplinary Social Sciences, 6(2), 199-216.

Kane, Mary J. y Greendorfer, Susan L. (1994), “The media's role in accommodating and resisting stereotyped images of women in sport", en Pamela J. CREEDON (ed.) Women, 
media and Sport: Challenging gender values (pp. 28-44), Sage Publications, Thousand Oaks, California.

Latorre, Pedro et al. (2007), "Mujer, deporte y medios de comunicación", en Revista digital de Buenos Aires, 11(106).

López Díez, Pilar (ed.) (2004), Manual de Información en género, IORTV (RTVE) e Instituto de la Mujer, Madrid.

López Díez, Pilar (2011), Deporte, mujeres y medios de Comunicación. Sugerencias y recomendaciones, Consejo Superior de Deportes, Madrid.

Rojas, José Luis (2010), "La construcción de las noticias deportivas desde una mirada androcéntrica. De la invisibilidad a los estereotipos de la mujer deportista", en Vivat Academia, (113), 1-15.

Sainz de Baranda, Clara (2013a), "Mujeres y deporte en los medios de comunicación. Estudio de la prensa deportiva española (1979-2010)" [http://e-archivo.uc3m.es/handle/10016/16505].

Sainz de Baranda, Clara (2013b): "La mujer en la prensa deportiva: dos perfiles", en Cuadernos de psicología del deporte, vol.14, 1, 91-102

Vigara, Ana María (2008), "Periodismo deportivo en España: sexismo discursivo y discriminación de género", en Guerrero Salazar, Susana y Núñez Cabezas, Emilio Alejandro, Nuevas tendencias de la lengua española en los medios de comunicación, VG Ediciones, Málaga. 